RECYT

Año 22 / № 33 / 2020 / 20-26

\title{
Aislamiento e identificación de hongos asociados a llex paraguariensis St. Hil.
}

\section{Isolation and identification of fungi associated with Ilex paraguariensis St. Hil.}

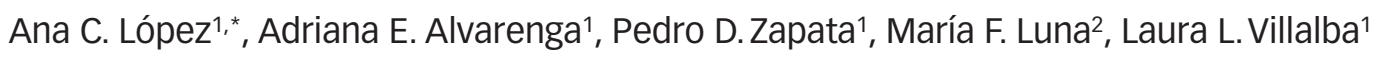 \\ 1- Laboratorio de Biotecnología Molecular, Instituto de Biotecnología Misiones, Facultad de \\ Ciencias Exactas Químicas y Naturales, UNaM, CP3300, Posadas, Misiones, Argentina. \\ 2- Centro de Investigación y Desarrollo en Fermentaciones Industriales (CINDEFI), CCT-La Plata CONICET, CIC-PBA, \\ Departamento de Química, Facultad de Ciencias Exactas, Universidad Nacional de La Plata, La Plata, Argentina. \\ *E-mail: anaclara_lopez@yahoo.com.ar
}

\section{Resumen}

Recibido el 19 de marzo de 2019, Aprobado el 05 de marzo de 2020.

\begin{abstract}
El cultivo de Ilex paraguariensis es importante en el norte de Argentina, principalmente en la provincia de Misiones. En los últimos años se ha observado la presencia de diferentes síntomas de enfermedades causadas por hongos de los cuales no se conoce agente causal, epidemiología y daño económico. En este estudio, se aislaron hongos de hojas de yerba mate que presentaban síntomas visibles de lesiones foliares. Cinco aislados (Alternaria, Colletotrichum, Phoma y Pilidium) fueron seleccionados por sus características micro y macromorfológicas. Estos hongos fueron identificados utilizando un microscopio óptico y claves morfológicas. Se realizaron ensayos de patogenicidad en hojas y en plantas de un año de yerba mate. Los resultados mostraron que Colletotrichum sp. LBM 183 y Phoma sp. LBM 207 son patógenos de hoja de yerba mate capaces de desarrollarse en el tejido. Mientras que Alternaria sp. LBM 186 y Pilidium sp. LBM 208 fueron capaces de enfermar la planta ingresando por la raíz de yerba mate.
\end{abstract}

Palabras clave: Yerba mate; Fitopatógenos; Identificación; Claves morfológicas; Ensayos de patogenicidad.

\section{Abstract}

The cultivation of Ilex paraguariensis is important in northern Argentina, mainly in Misiones province. The presence of different symptoms of diseases caused by fungi has recently been observed. Neither the causative agents nor the epidemiological or economic damages have been identified yet. In this study, fungi were isolated from yerba mate leaves that showed visible symptoms of foliar lesions. Five isolated samples: Alternaria, Colletotrichum, Phoma and Pilidium; which were selected because of both, their micro and macro morphological characteristics. These fungi were identified by using an optical microscope together with morphological keys. Pathogenicity tests were carried out on yerba mate leaves and on one-year-old plants. The results showed that Colletotrichum sp. LBM 183 and Phoma sp. LBM 207 are pathogens typical of the yerba mate leaves capable of developing within the plant tissue, while Alternaria sp. LBM 186 and Pilidium sp. LBM 208 were able to sicken the plant by entering into the yerba mate root.

Keywords: Yerba mate; Phytopathogens; Identification; Morphological keys; Pathogenic assay.

\section{Introducción}

La yerba mate (Ilex paraguariensis St. Hil.) es una especie que se encuentra en bosques lluviosos en el suroeste de Paraguay, sur de Brasil y norte de Argentina (1). Este árbol es un cultivo regional muy valioso ya que sus hojas se transforman en una bebida tradicional llamada mate (2). Actualmente, en nuestro país existen 169.633 hectáreas cultivadas de yerba mate (3) de las cuales un $87 \%$ se encuentran en la provincia de Misiones, Argentina. En las últimas décadas, un creciente aumento del área de cultivo genera una serie de problemas fitosanitarios por el aumento de la disponibilidad de hospederos, manejo y cultivo de las plantas, prácticas inadecuadas, aumento del estrés fisiológico por los bajos niveles de sombramiento y abundancia del cultivo en áreas inadecuadas.

Si bien la República Argentina es la primera productora mundial de yerba mate, los estudios de patologías afectando al cultivo son escasos (4). En la última década, se ha observado la presencia de distintos síntomas de enfermedades en las plantaciones de yerba mate de esta región, de las que no se conoce el agente causal, epidemiología y 
potencial de daño económico (5). La información obtenida de la literatura sobre hongos de yerba mate, revelan más de 120 especies registradas en trabajos científicos publicados en un período entre 1908 y 2002, pero mucho de estos trabajos tienen como objetivo la descripción taxonómica, sin profundizar en estudios de patogenicidad (Colombo 2002). Uno de los problemas que afecta la productividad de los cultivos, es la infección foliar por hongos fitopatógenos. Entre los numerosos hongos que se asocian de distintas formas al follaje de yerba mate solo unos pocos causan verdaderos daños y preocupación a los productores yerbateros. Se destacan los causantes de Antracnosis (Colletotrichum spp.), del Hollín de la yerba mate (Asterina sphaerelloides); de la Mancha Negra (Cylindrocladium spathulatum), de Mancha gris o cercosporiosis (Pseudocercospora mate), además de algunas virosis (3).

En el proceso de "domesticación" de la yerba, se van sumando los efectos de las técnicas culturales (densidad, distanciamiento, labores, fertilización) y la erosión genética de las características de resistencia que las plantas poseían creciendo en su ambiente natural. La tendencia a la homogeneidad en ambos aspectos favorece el desarrollo de enfermedades. En el ambiente selvático, la acción de las enfermedades es contrarrestada por el ecosistema natural. En un ambiente agrícola, como el hospedante es abundante y homogéneo y la biodiversidad pequeña, los enemigos naturales son pocos para equilibrar las poblaciones de hongos y bacterias patógenas. Esto hace pensar que los problemas por enfermedades se agudizarán en el futuro (Burtnik 2006).

Por lo expuesto, es importante profundizar en el conocimiento a los productores principalmente de las posibles amenazas patógenas que afectan estos cultivos, ya que existen pocos reportes sobre este tema. Por lo tanto, el objetivo del presente trabajo fue aislar e identificar hongos causantes de síntomas visibles en hojas de yerba mate. La identificación realizada se llevó a cabo utilizando técnicas macro y microscópicas. Una vez identificados los aislados, el siguiente objetivo del trabajo fue realizar pruebas de patogenicidad in vitro en hojas de yerba mate sanas en cámara húmeda e in vivo en plantas juveniles de yerba mate. En base a los resultados obtenidos y la bibliografía disponible se determinó si estos aislados podrían ser potenciales patógenos de yerba mate o no.

\section{Materiales y Métodos}

\section{Recolección de material vegetal}

Se seleccionaron muestras de hojas de plantas de yerba mate con síntomas visibles de enfermedad (Figura $1 \mathrm{~A}$ y B). La recolección se llevó a cabo en el vivero propiedad de la Fundación Alberto Roth, Santo Pipó, Misiones, Argentina, localización geográfica: $27^{\circ} 08^{\prime} 24^{\prime \prime} \mathrm{S} 55^{\circ} 24^{\prime} 31^{\prime \prime} \mathrm{O}$ (Figura 2).

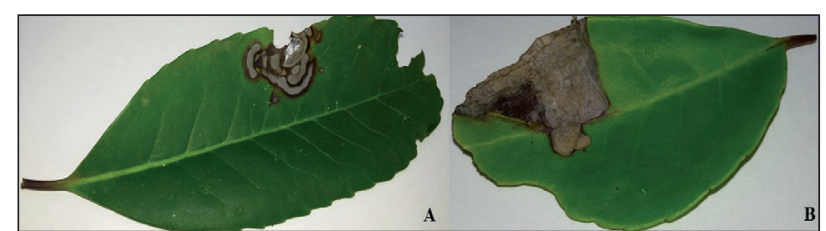

Figura 1: Muestras recolectadas de hojas con síntomas.

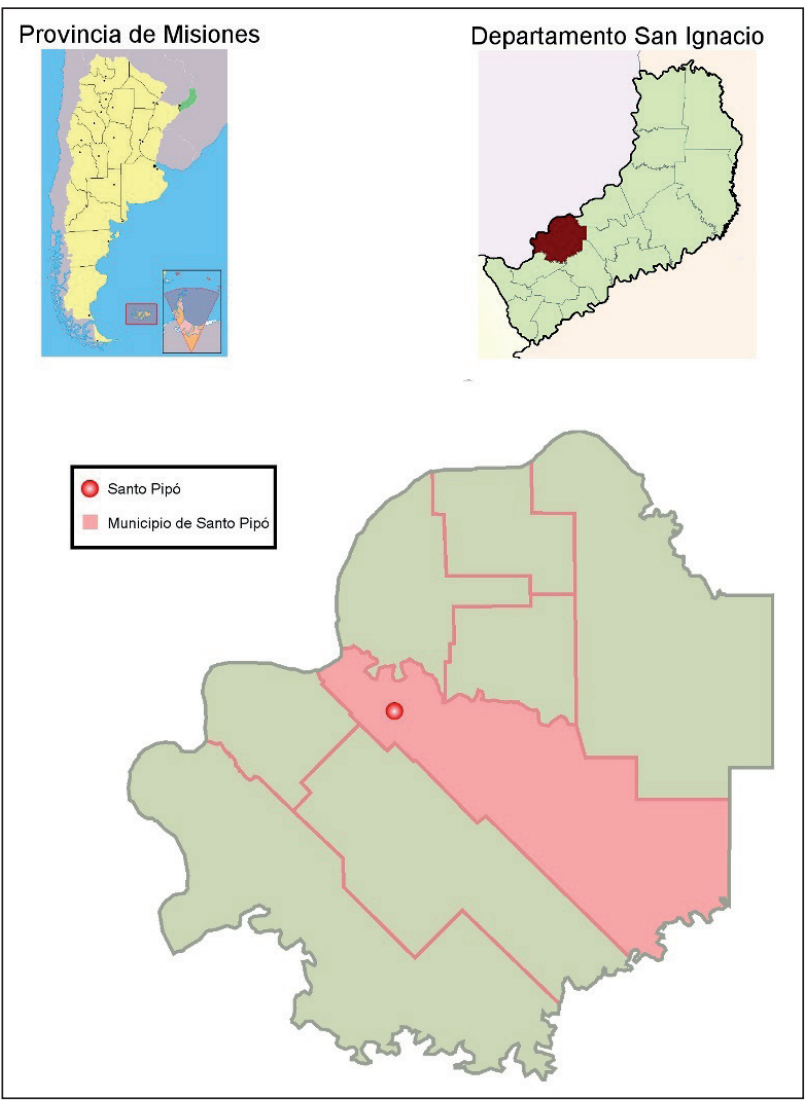

Figura 2: Santo Pipó, Misiones, Argentina. Localización geográfica: $27^{\circ} 08^{\prime} 24^{\prime \prime} \mathrm{S} 55^{\circ} 24^{\prime} 31^{\prime \prime} \mathrm{O}(7)$.

\section{Aislamiento de endófitos de yerba mate}

Las hojas se cortaron en pequeños trozos de $1 \mathrm{~cm}$ por 1 $\mathrm{cm}$ representando tanto las partes de la hoja con síntomas de infección como partes del tejido sano. Luego, se realizó un protocolo de desinfección, el cual consistió en un lavado con hipoclorito de sodio al $2 \% \mathrm{v} / \mathrm{v}$ durante 3 minutos y 3 lavados con agua destilada estéril durante 2 minutos. Las muestras se colocaron en placas de Petri con medio agaragua al $2 \% \mathrm{p} / \mathrm{v}$ (AA $2 \%$ ) y se incubaron a $28 \pm 1^{\circ} \mathrm{C}$ con luz constante, hasta la visualización de colonias fúngicas.

\section{Identificación de los endófitos aislados}

Los aislados se desarrollaron a $28 \pm 1^{\circ} \mathrm{C}$ en presencia de luz constante en papa-dextrosa agar (PDA) para inducir la formación de estructuras reproductivas. Luego de 5 días de incubación, se registraron características macroscópicas como color de anverso y reverso de la colonia. A su vez, las placas fueron observadas a simple vista bajo lupa.

Se realizaron montajes de micelio crecido de las colo- 
nias en portaobjetos y se realizó una tinción con azul de lactofenol para la observación en el microscopio óptico. Se realizó la observación de diferentes estructuras en el microscopio junto con la utilización de diferentes claves taxonómicas como las de Barnett \& Hunter (8) y Pitt \& Hockings (9).

\section{Ensayos de patogenicidad in vitro}

Para evaluar la patogenicidad de los hongos aislados de hojas de yerba mate, se recolectaron hojas sanas de plantas de yerba mate de doce meses de vida. Las hojas se desinfectaron realizando lavados con hipoclorito de sodio al $2 \%$ durante 2 minutos y 3 lavados sucesivos con agua destilada estéril. Luego, se dejaron secar y se colocaron con la cara abaxial hacia arriba en bandejas plásticas previamente desinfectadas con alcohol $70 \%$. Se les realizó un pequeño corte con bisturí estéril a ambos lados del nervo de la hoja y sobre cada corte se colocó 1 taco de $6 \mathrm{~mm}$ con micelio en desarrollo de los aislados seleccionados. El control consistió en hojas desinfectadas con cortes sin agregado de tacos. Las hojas se cubrieron con gasa estéril humedecida con agua destilada estéril y las bandejas se sellaron con parafilm. Se incubaron a $28 \pm 1^{\circ} \mathrm{C}$ durante 7 días en presencia de luz. Para este ensayo, se utilizó un diseño aleatorizado con seis tratamientos y tres repeticiones, donde la unidad experimental fue la hoja y la variable de estudio fue daño ocasionado por el microorganismo en la hoja. El daño se determinó utilizando una escala arbitraria en comparación a lo observado en el control. Para corroborar que el daño ocasionado en el tejido vegetal fue producido por el microorganismo inoculado, se realizó el reaislamiento de los hongos.

\section{Ensayos de patogenicidad en plantas de yerba mate}

Se realizó un segundo ensayo de patogenicidad en la raíz de la planta de yerba para observar si estos aislados son capaces de afectar también este tejido vegetal. Para este ensayo, se realizó un diseño experimental completamente aleatorizado con seis tratamientos (cinco aislamientos y un control), y seis repeticiones donde la unidad experimental fue la planta, de doce meses de vida. La duración del ensayo fue de 4 meses. Cada planta se inoculó con $5 \mathrm{ml}$ de una suspensión en Tween 80 al $0,1 \%$ de $10^{5}$ propágulos/ $\mathrm{ml}$ de los aislados. El control consistió en el agregado de agua destilada a las plantas. Las plantas se mantuvieron en cámara de incubación a una temperatura de $24^{\circ} \mathrm{C}$ durante el período de luz con una duración de 12 horas y con una intensidad de alrededor de 2000 Lumex, y una temperatura de $20^{\circ} \mathrm{C}$ durante el período de oscuridad con una duración de 12 horas. Al finalizar el ensayo, se realizó peso seco total, de la raíz y parte aérea de las plantas. También se determinó incidencia y severidad de las plantas ensayadas.

La incidencia se determinó utilizando la siguiente fórmula:
Incidencia (I): $\frac{N^{\circ} \text { de plantas enfermas }}{\text { Total (sanas }+ \text { enfermas)de plantas observadas }} \times 100$

Los síntomas fueron evaluados según la siguiente tabla:

Tabla 1: Escala de severidad

\begin{tabular}{|c|c|}
\hline Escala & Síntoma \\
\hline 0 & 0 a $5 \%$ de manchas en parte aérea \\
\hline 1 & 5 a $25 \%$ de manchas en la parte aérea \\
\hline 2 & 25 a $50 \%$ de manchas en la parte aérea \\
\hline 3 & $>50 \%$ de manchas en la parte aérea \\
\hline
\end{tabular}

\section{Análisis estadísticos}

Los datos de peso seco obtenidos en el ensayo de patogenicidad en plantas se probaron para la distribución normal con la prueba de Shapiro-Wilk y la homogeneidad de varianza, dependiendo los resultados, fueron analizados con ANOVA o Kruskal-Wallis. Se realizó un posterior análisis con la prueba de Fisher con un 5\% de confianza utilizando el programa Statgraphics Centurion XV versión 15.2.06.

\section{Resultados y Discusión}

\section{Aislamiento e identificación de endófitos de yerba mate}

Se realizaron 15 aislamientos de hongos con diferentes características macroscópicas y microscópicas. Mediante técnicas macro y microscópicas se lograron identificar 6 aislados, los cuales fueron nombrados según las siglas de la colección de cultivos del Instituto de Biotecnología Misiones: Colletotrichum sp. LBM 183, Alternaria sp. LBM 186, Phoma sp. LBM 189, Phoma sp. LBM 207 y Pilidium sp. LBM 208.

\section{Género Colletotrichum}

La cepa LBM 183 se pudo identificar como Colletotrichum sp. La colonia crecida en PDA a los 7 días presentó micelio de color gris oscuro en el anverso (Figura $3 \mathrm{~A}$ ) y color negro en el reverso de la colonia (Figura 3 B). En la lupa se pudieron observar hifas finas y gruesas y a su vez, un aglomerado de estructuras (Figura $3 \mathrm{C}$ ). En el microscopio utilizando aumento de 40X se observó aglomerado de hifas hialinas septadas, conidios de gran tamaño hialinos de forma cilíndrica con extremo redondeado y setas color marrón, que son característicos del género (Figura 3 D). 


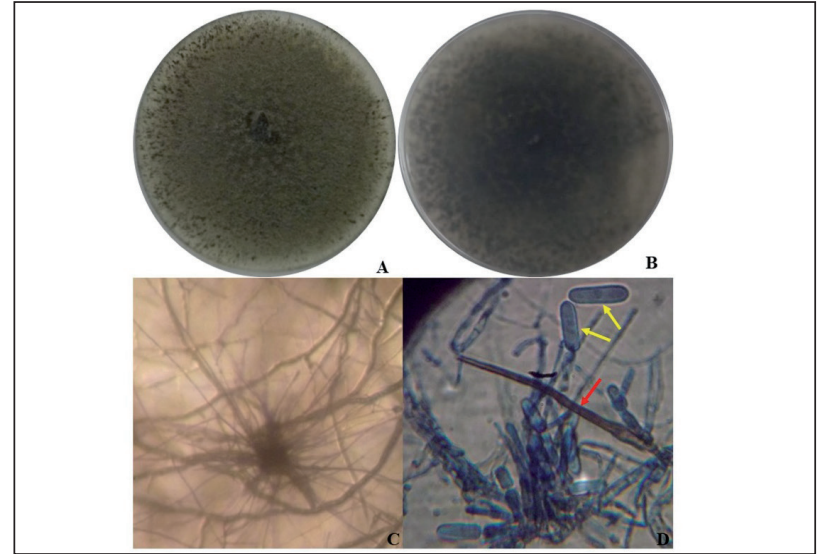

Figura 3: Género Colletotrichum. A. Anverso y B. Reverso de la colonia de LBM 183 crecida en PDA durante 7 días C. Placa crecida en PDA observada en la lupa D. Observación en microscopio con aumento $40 X$, flecha amarilla señala los conidios y flecha roja hace referencia a la seta observada.

\section{Género Alternaria}

La cepa LBM 186 fue identificada como Alternaria sp. El anverso de la colonia crecida en PDA se observó color marrón claro y de aspecto algodonoso (Figura $5 \mathrm{~A}$ ), mientras que el reverso se observó marrón oscuro en el centro de la colonia y marrón más claro hacia el borde de la placa (Figura 5 B). En la lupa se observaron cadenas y agrupaciones de conidios (Figura $5 \mathrm{C}$ ) que luego se observaron al microscopio óptico, donde se pudo determinar la disposición de 3 a 5 conidios en cadena. Los conidios presentaron forma ovoide con 6 o más septos en su interior e hifas hialinas septadas (Figura 5 D).

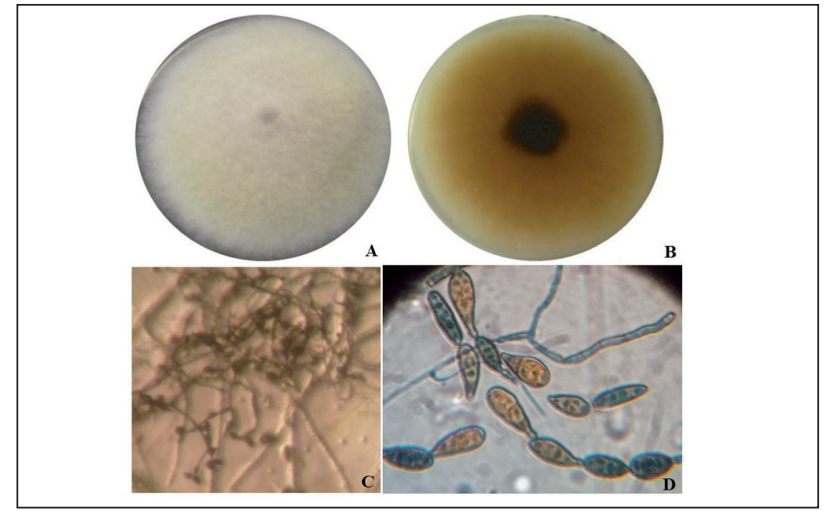

Figura 5: Género Alternaria. A. Anverso y B. Reverso de la colonia de LBM186 crecida en PDA durante 7 días C. Placa crecida en PDA durante 7 días observada en la lupa D. Foto de microscopía con aumento $40 \mathrm{x}$.

\section{Género Phoma}

Las cepas LBM 187 y LBM 207 fueron identificadas como Phoma sp. La colonia de lado anverso de LBM 187 presentó color marrón claro en el centro y blanco hacia los bordes con aspecto algodonoso (Figura $6 \mathrm{~A}$ ), mientras que el reverso se caracterizó por presentar un color verde oscuro casi negro (Figura 6 B). El anverso de la colonia de LBM 207 presentó un color rosado (Figura 6 C), mientras que el reverso se observó de color marrón con la formación de anillos concéntricos alrededor del centro de la colonia (Figura 6 D). Las colonias de ambas cepas observadas bajo la lupa presentaron estructuras globosas (Figura $6 \mathrm{E}$ ) que mediante observación microscópica se determinó que esas estructuras corresponden a picnidios característicos del género Phoma (Figura 6 F). También se observó la presencia de conidios unicelulares e hifas hialinas estériles característicos de este género.

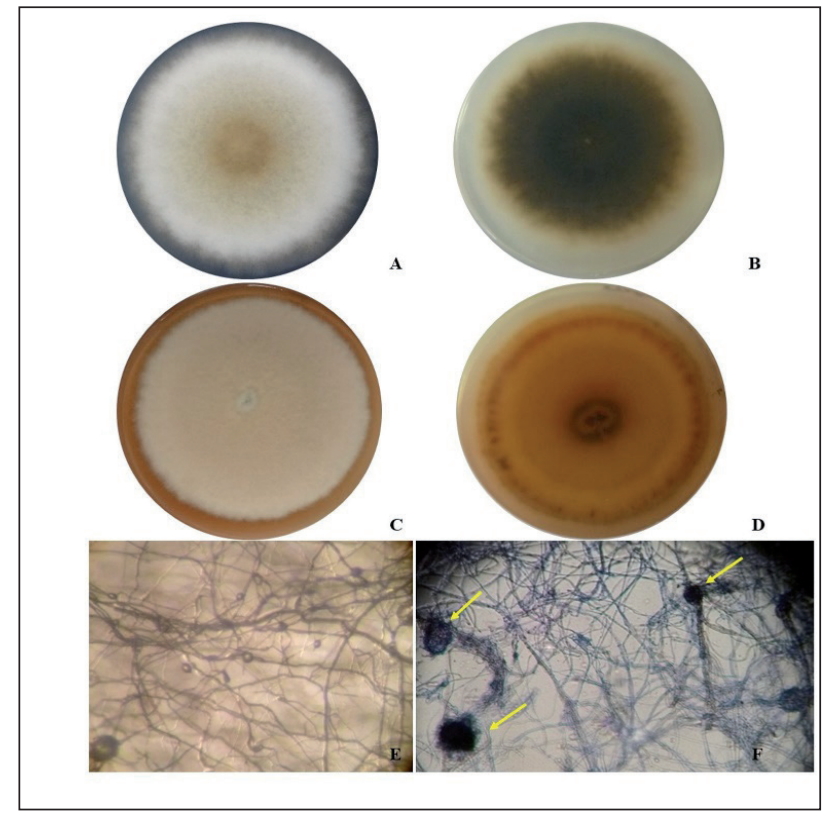

Figura 6: Género Phoma. A. Anverso y B. Reverso de la colonia de LBM 189 crecida en PDA durante 7 días C. Anverso y D. Reverso de la colonia de LBM 207 crecida en PDA durante 7 días E. Placa crecida en PDA durante 7 días observada en la lupa F. Foto de microscopía con aumento $10 \mathrm{X}$, las flechas indican la presencia de picnidios

\section{Género Pilidium}

La cepa LBM 208 fue identificada como Pilidium sp. La colonia presentó color blanco del lado anverso (Figura 7 A) y color amarillento del reverso (Figura 7 B) luego de 7 días de incubación en PDA. Esta cepa se caracterizó por ser de crecimiento lento, ya que a los 12 días de desarrollada la colonia en PDA se observó, tanto del lado anverso como reverso, una pigmentación color marrón con formación de círculos concéntricos y formación de picnidios (Figura $7 \mathrm{C}$ ). En el microscopio, se observaron hifas hialinas estériles luego de 7 días de incubación en PDA; en cambio, luego de 12 días de incubación en PDA, se pudieron observar pequeñas conidias fusiformes con extremos puntiagudos aglomeradas en masa (Figura 7 D). 


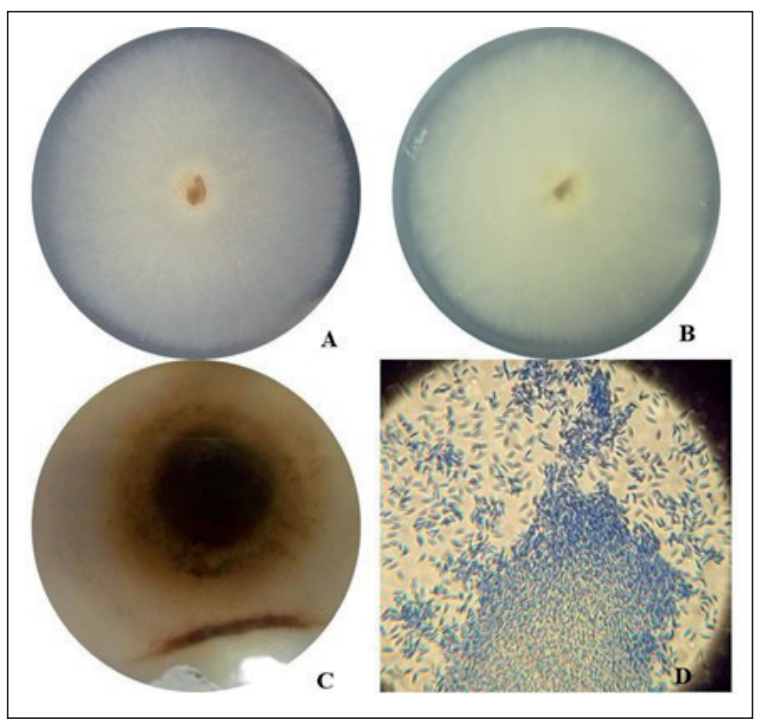

Figura 7: Género Pilidium. A. Anverso y B. Reverso de la colonia de LBM 208 crecida en PDA durante 7 días C. Reverso de la colonia de LBM208 crecida en PDA durante 12 días D. Foto de microscopía con aumento $40 \mathrm{X}$ de la colonia crecida durante 12 días en PDA

\section{Ensayos de patogenicidad in vitro en cámara húmeda}

En el ensayo realizado en cámara húmeda se pudo observar que el aislamiento que mayor severidad produjo en el tejido de la hoja en comparación con el control (Figura 8 A) fue Phoma sp. LBM 207 (Figura 8 F). Se pudo observar que este aislado produjo una mancha necrótica en el tejido de la hoja. Colletotrichum sp LBM 183 y Alternaria sp. LBM 186 fueron capaces de dañar la hoja en menor proporción que LBM 207 (Figura 8 B y D), mientras que LBM 189 Phoma sp. y LBM 208 Pilidium sp. (Figura 8 E y G) fueron los que menor daño causaron a la hoja en comparación con el control.

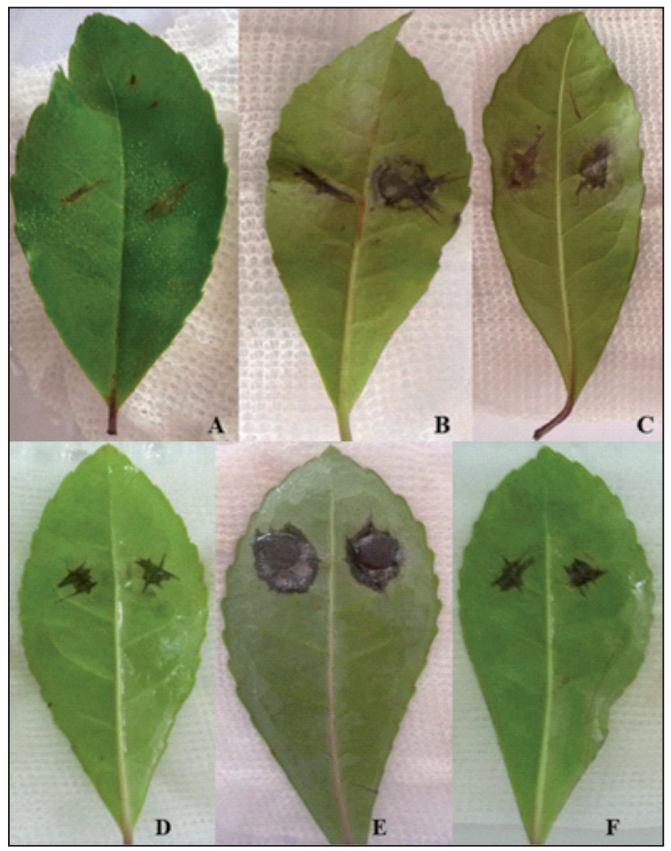

Figura 8: Ensayo de patogenicidad. Fotografías de hojas de yerba mate luego de 7 días de incubación a $28^{\circ} \mathrm{C}$. A. Hoja sin inóculo: control. Hojas inoculadas con: B. Colletotrichum sp. LBM 183. C. Alternaria sp. LBM 186 D. Phoma sp. LBM 189 E. Phoma sp. LBM 207. F. Pilidium sp. LBM 208
En las hojas inoculadas con los diferentes aislados, se pudo observar la presencia de estructuras reproductivas de LBM 183, LBM 186, LBM 207 y LBM 208 mediante observación al microscopio óptico (Figura 9). Esto nos da un indicio de que el hongo fue capaz de reproducirse en el tejido vegetal en las condiciones ensayadas.

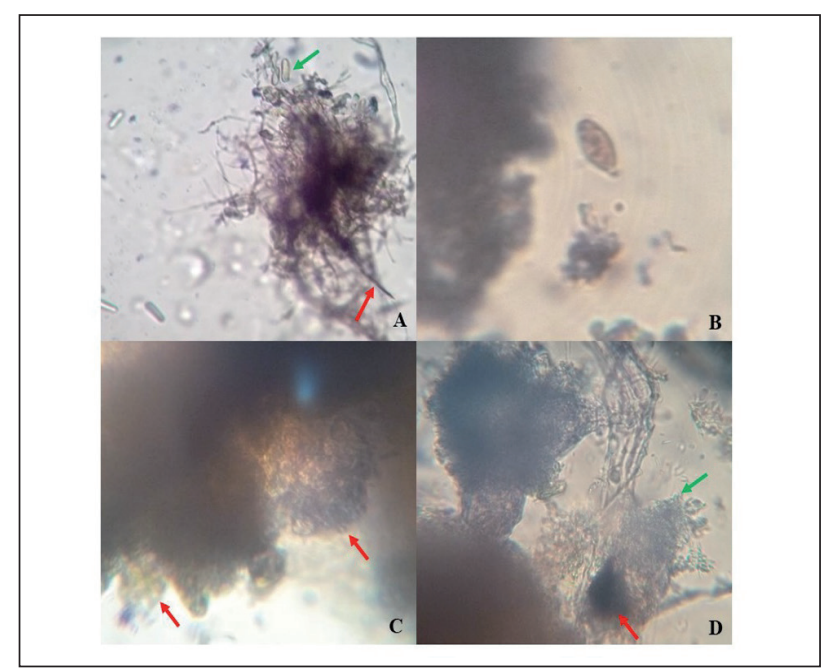

Figura 9: Fotografías tomadas de hojas inoculadas observadas en el microscopio óptico. A. Flecha roja y flecha verde indica setas y conidios, respectivamente, de Colletotrichum sp. LBM 183 en 10X B. Conidio de Alternaria sp. LBM 186 cerca de la hoja en 40X C. Flechas rojas indican picnidios de Phoma sp. LBM 207 formado en la hoja en 40X D. Flechas roja y verde indican picnidio y conidias, respectivamente, de Pilidium sp LBM 208 en 40X.

En el trabajo publicado por Rybak (5) se reporta a Phoma sp. como un patógeno de hojas de yerba mate en donde se muestran estructuras reproductivas similares a las observadas en la Figura $9 \mathrm{C}$, por lo que podemos decir, que Phoma sp. LBM 207 es capaz de reproducirse y desarrollarse en la hoja, ocasionándole un daño visible al tejido. Por otro lado, Gomes (16) en su trabajo ha logrado asociar la antracnosis de la yerba mate a organismos de la especie Colletotrichum acutatum, donde existe una prevalencia de la infección en hojas jóvenes. Por lo expuesto, podemos afirmar que Colletotrichum sp. LBM 183 y Phoma sp. LBM 207 son patógenos de hoja de yerba mate.

Para poder obtener un mejor diagnóstico sobre estos posibles patógenos, se debería realizar un ensayo bajo las mismas condiciones, pero con mayor duración de tiempo, para que el hongo tenga tiempo para poder desarrollarse y sea capaz de infectar el tejido.

\section{Ensayos de patogenicidad en plantas de yerba mate}

Todas las cepas inoculadas mostraron una incidencia del 50\% o mayor en plantas de yerba mate. Se observó un índice de síntomas de 1 , es decir, 5 a 25\% de manchas en las hojas, en las plantas tratadas con Alternaria sp. LBM 186 y Phoma sp. LBM 189. Las plantas tratadas con las otras cepas mostraron un índice de síntomas de 2, por lo cual se observaron de un $25 \%$ a un $50 \%$ de manchas en las hojas de las plantas (Tabla 2). 
Tabla 2: Incidencia y síntomas de las plantas de yerba en presencia de los diferentes hongos inoculados.

\begin{tabular}{|l|c|c|c|c|}
\hline Cepa & Género & Repeticiones & Incidencia (\%) & Severidad \\
\hline LBM183 & Colletotrichum sp. & 6 & $66,7 \pm 0,52$ & 2 \\
\hline LBM186 & Alternaria sp. & 6 & $50 \pm 0,55$ & 1 \\
\hline LBM189 & Phoma sp. & 6 & $66,7 \pm 0,52$ & 1 \\
\hline LBM207 & Phoma sp. & 6 & $66,7 \pm 0,52$ & 2 \\
\hline LBM208 & Pilidium sp. & 6 & $66,7 \pm 0,52$ & 2 \\
\hline
\end{tabular}

Los resultados de los pesos secos de las plantas mostraron que Alternaria sp. LBM 186 fue la única cepa capaz de disminuir el peso total, de raíz y parte aérea de la planta con diferencias significativas en comparación con el control (peso total $\mathrm{p}=0,0003$; peso seco raíz $\mathrm{p}=0,0043$; peso seco parte aérea $\mathrm{p}=0,013$ ). Phoma $\mathrm{sp}$. LBM 207 mostró diferencias significativas con el control de menor peso seco total y de raíz. Las demás cepas utilizadas no disminuyeron el peso seco de las plantas en comparación con el control (Figura 10).

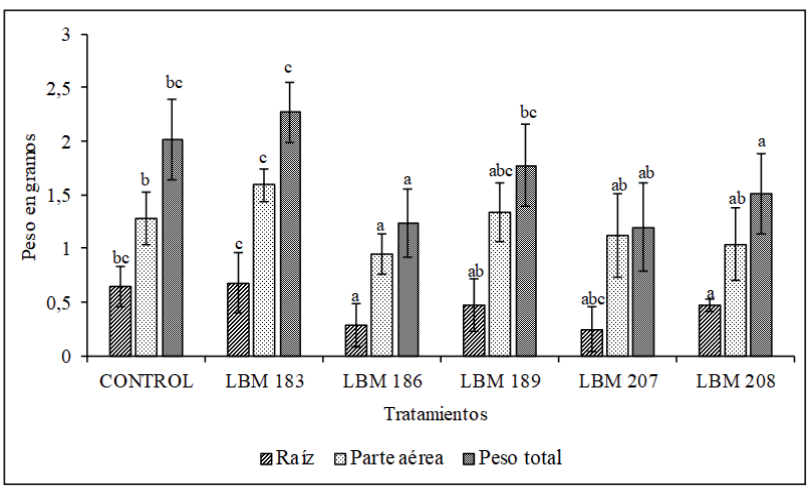

Figura 10: Promedio de peso seco del ensayo de patogenicidad en plantas. Las letras iguales arriba de las barras indican grupos homogéneos. Referencias: Colletotrichum sp. LBM 183, Alternaria sp. LBM 186, Phoma sp. LBM 189, Phoma sp. LBM 207 y Pillidium sp. LBM 208.

Estos resultados demostraron la capacidad de Alternaria sp. y Pilidium sp. de afectar el tejido vegetal de las plantas de yerba inoculadas. No se observaron mayores daños cuando se inocularon en la hoja de yerba mate, por lo que podemos suponer que dichos hongos probablemente sean endófitos de hojas de yerba mate viviendo saprófitamente.

Por el momento, no se han encontrado trabajos que indiquen a Alternaria sp. y Pillidium sp. como posibles patógenos de yerba mate, pero sí, se han encontrado investigaciones que reportan a estos géneros como patógenos de una amplia variedad de cultivos tanto en hoja como en raíz. Especies del género Alternaria han sido reportadas como patógenos de una vasta cantidad de cultivos destinados a la alimentación humana, como patógenos de tomate (10), trigo y sorgo (11), entre otros. Se registró la presencia de hongos del género Alternaria en suelos donde se realizan monocultivos de yerba mate (12). Se ha reportado la aparición de este género como endófitos en un cultivo que se desarrolla bajo las mismas condiciones y con características fisiológicas muy similares a las de yerba mate, como es el té Camellia sinensis (13). Las especies del género Pilidium son han sido reportadas como agente causal de manchas foliares en plantas de frutilla (14), así como también se ha detectado casos de pudrición de la fruta en cultivares de pera (15) y en otros frutos. Pero no se han encontrado trabajos que asocien este hongo a enfermedades en cultivos de Ilex paraguariensis.

Por lo expuesto, Alternaria sp. LBM 186 y Pilidium sp. LBM 208 son potenciales patógenos de yerba mate capaces de ingresar por la raíz de la planta y afectando sistemáticamente dicho cultivo produciendo daños con síntomas visibles. Para corroborar la patogenicidad de estos géneros, se debería realizar pruebas de patogenicidad en plantas de yerba mate con inoculaciones del hongo en estudio en el órgano vegetal del que fueron aislados.

\section{Conclusiones}

Phoma sp. LBM 207 y Colletotrichum sp. LBM 183 fueron capaces de producir signos en las hojas de yerba mate, por lo que son potenciales patógenos de hoja de yerba mate. Alternaria sp. LBM 186 y Pilidium sp. LBM 208 son reportados por primera vez como potenciales patógenos de yerba mate.

Este trabajo es de gran importancia regional ya que se centra en un problema de gran relevancia que afecta a la producción yerbatera. La infección de yerbales por fitopatógenos produce grandes pérdidas en la productividad, por lo que conocer el agente causal y las condiciones en las cuales se produce nos lleva a poder desarrollar herramientas que permitan el manejo y control de estos patógenos.

\section{Agradecimientos}

Los autores de este trabajo agradecemos a quienes financiaron esta investigación a través de un proyecto de innovación "Universidades Agregando Valor 2017" brindado por Secretaría de Políticas Universitarias Resolución N4285-APN-SECPU\#ME/17 y el proyecto PICT-START UP 2017-0007 otorgado por la Agencia Nacional de Promoción Científica y Tecnológica. También agradecemos a la Fundación Alberto Roth por proveer los ejemplares para la realización de los ensayos.

\section{Referencias}

1. Gunther, D; Correa, M; Lysiak, E. Estudios socioeconómicos de la sustentabilidad de los sistemas de producción y recursos naturales, Ediciones INTA, Buenos Aires. pp.117. 2008. ISSN 1851-6955.

2. Bergottini, V.M; Otegui, M.B; Sosa, D.A; Zapata, P.D; Mulot, M; Rebord, M, Zopfi, J; Wiss, F; Benrey, B.; Junier, P. Bio-inoculation of yerba mate seedlings (Ilex paraguariensis St. Hil.) with native plant growth-promoting rhizobacteria: a sustainable alternative to improve crop yield, Biology and Fertility of Soils. 53 (6): p.749-755. 2015. http:// 
dx.doi.org/10.1007/s00374-015-1012-5.

3. INYM. Relevamiento de yerbales (2018). Available at: https:/www.inym.org.ar/el-inym-realiza-un-minucioso-relevamiento-de-plantaciones-con-su-sistema-deinformacion-geografica/. (Verified 6 Feb. 2019).

4. Auer, C. G. y Grigoletti Jr., A. Associação de fungos com Ilex spp., Boletim de Pesquisas Florestais, 45: p. 109-124. 2002. https://www.alice.cnptia.embrapa.br/bitstream/ doc/306654/1/pag109124.pdf

5. Rybak, M; Rybak, R; Cabrera, MG; Alvarez, RE. Enfermedades de Yerba Mate y Té en Misiones y Norte de Corrientes. Argentina: INTA EEA Cerro Azul (Miscelánea No 66), 2014. 32 p.

6. Santo Pipó, Misiones, Wikipedia (2007) [Online]. Available at https://es.wikipedia.org/wiki/Santo_Pip\%C3\%B3\#/ media/File:Municipio_Santo_Pip\%C3\%B3_en_departamento_San_Ignacio.png. 2007 (Verified 25 Ene. 2019).

7. Barnet, H.L. y Hunter, B.B. Illustrated Genera of Imperfect Fungi, APS Press, Minnesota. 218 p.1998.

8. Pitt, J.I. y Hocking, A.D. Fungi and food spoilage, Springer, New York. 143 p. 2009. http://dx.doi.org/10.1007/9780-387-92207-2.

9. $\mathrm{Xu}, \mathbf{M}$; He, R; Zeng, C.B; Liu, Y; Tang, G.H; Tang, H. Isolation and molecular identification of Colletotrichum gloesporioides causing brown spot disease of Camelli oleifera in
Hainan of China, Journal of Phytopathology. 165 (6): p.380-386. 2017. http://dx.doi.org/10.1111/jph.12571.

10. Pose, G.; Ludemann, V.; Segura, J.; Fernandez Pinto, v. Mycotoxin production by Alternaria strains isolated from tomatoes affected by blackmold in Argentina. Mycotox. Res. 20: 80-86. 2004.

11. Fakhrunnisa, M.H.H.; Ghaffar, A. Seedborne mycoflora of wheat, sorghum and barley. Pak. J. Bot. 38: 185-192. 2006.

12. Borges, L.R. Diversidade de fungos filamentosos em solo de monocultivo de erva-mate, Ilex paraguariensis St. Hil. Revista Acadêmica, Ciências Agrárias e Ambientais, v.9, n.2, p.185-194, 2011. http://dx.doi. org/10.7213/cienciaanimal.v9i2.11786

13. Gomes, N.S.B.; Júnior, A.G.; Auer, C.G.; Wielewski, P.; Valle, G.M. Patogenicidade de Colletotrichum acutatum em folhas destacadas de erva-mate. Boletim de Pesquisas Florestais, v.43, p.151-154, 2001. https://www.alice.cnptia. embrapa.br/alice/bitstream/doc/305902/1/gomes1.pdf.

14. Golebniak, B.; Jarosz, A. First report of tan-brown rot (Hainesia lythri) on strawberry fruits in Poland. Phytopatol Pol. 31, 57-60. 2004.

15. Sayari, M.; Babaeizad, v.; Fathi, J. First report of Pilidium concavum as the causative agent of tan-brown rot of Prunus domestica fruits in Iran. J Plant Pathol. 2013. 